\title{
Organizational Performance: Strategic Persistence Versus Strategic Change
}

\author{
Rolf D. Dixon \\ West Texas A\&M University \\ Canyon, Texas \\ Kimberly B. Boal \\ Texas Tech University \\ Lubbock, Texas
}

\begin{abstract}
The relationship of strategy to organizational performance has been of great interest to strategic management scholars. However, the relative contribution to organizational performance of the content of strategic decisions as opposed to the implementation of strategic decisions is not agreed upon in the literature. If it is primarily what strategy you select that leads to higher performance, then strategic change is good. On the other hand, if it is primarily how well you implement any given strategy that leads to higher performance, then strategic persistence is good. This study considers the relative contribution of strategic change versus strategic persistence as they relate to organizational performance in the banking industry.
\end{abstract}

\section{Introduction}

Two views have been espoused by strategic management scholars relating to the relationship of strategy to performance. One suggests that a firm's performance ultimately will depend on the content of the organization's strategic decisions - what an organization decides to do. The Miles and Snow (1978) and Porter (1980) strategy typologies are well known major contributors to the idea of generic strategies that lead to higher organizational performance when appropriately matched with a firm's current operating environment. This view would suggest that if an organization is not performing well with its current strategy the answer will be to change to another strategy.

Another view, espoused by scholars such as Galbraith (1983), Parnell (1994), and Peters (1984), suggests that an organization's success will be based not on what strategy is selected, but, rather, on how well an organization manages its internal strategy implementation processes - internal capabilities developed over time. Taken from this perspective the organization that is not meeting its performance goals should seek to improve its internal implementation processes rather than change its strategic direction. 
This paper seeks to contribute to our understanding of the value of organizations maintaining their strategic direction over time (strategic persistence), as opposed to that of changing strategies, as it relates to the issue of resulting performance levels for those organizations.

The banking industry was utilized as the investigation arena for this study. Banking over the last 20 years has gone from a period of environmental stability, to a period of environmental instability; this allows an investigation of the impact of strategic persistence on performance within the context of both a stable industry environment and an unstable industry environment. Within each period (stable versus unstable) the performance level of firms that had pursued a constant strategy was compared to that of firms that had changed their strategy. Strategic groups, defined as collections of firms pursuing a common strategy, were utilized as the mechanism for this comparison. Firms that did not change their strategic group membership for the time period of this study are referred to as constant firms-firms persisting with a particular strategy. Firms that either entered or left mid-period a strategic group are referred to as shifting firms-firms exhibiting a change in their strategic direction.

Managers, driven by a need to establish and maintain high performance levels in their organization, have a vested interest in this question - is organizational performance a primary function of what an organization decides to do, or of how well it does that which it is already doing?

\section{Strategic Groups}

The concept of strategic groups was first introduced by Hunt (1972) in his dissertation study of the white goods industry. Strategic groups have been identified as collections of firms grouped by similar strategic actions and responses to a shared operating environment (Cool and Schendel, 1987). Over the 24 years that have followed Hunt's initial study, strategic group research has developed as a significant and popular arena for the investigation of organizational behavior and performance (Barney and Hoskisson, 1990; McGee and Thomas, 1986; Thomas and Venkatraman, 1988).

Fiegenbaum and Thomas (1995) have indicated that strategic groups act as important reference points for firms' strategic behavior. The use of strategic groups within the banking industry allowed collections of firms that are pursuing similar strategies.

Within a strategic group over time, there should be found some firms that have been members of that strategic group for a substantial period of time and some firms that are relatively new members of that strategic group. Segmenting these two types of firms within each strategic group makes possible the explicit investigation of the impact of strategic persistence, as identified by long-term strategic group membership, on firm performance. 


\section{Industry Environment}

A contextual issue also considered in this study was to what extent, if any, did the conditions of industry environmental stability and instability impact the relationship between strategic persistence and firm performance.

In terms of the management of strategy, the dimension of dynamism/instability, which involves a lack of predictable patterns, acts to reduce the ability of firms to individually and collectively understand what strategies produce the best performance results, and to have the time available to understand all the issues involved in the successful implementation of any given strategy. Further, Keats and Hitt (1988) indicated that the dimension of instability has a greater impact on an organization's performance than do either munificence or complexity, the other dimensions most commonly utilized to characterize the environment (Dess and Beard, 1984). Thus, the dimension of instability provided the ideal context for investigating the role of the environment on the issues of this study.

\section{Research Hypothesis}

\section{Strategic Persistence and Performance}

This research investigates the impact of strategic persistence within strategic groups on performance. For the purposes of this study, firms that remain within a particular strategic group for the duration of the stable or unstable period of time are referred to as "constant" member firms exemplifying strategic persistence. Firms that entered or left one or more strategic groups within the stable or unstable period of time are referred to as "shifting" member firms exemplifying strategic change. Specifically, to investigate the impact of strategic persistence versus strategic change on performance we test for statistically significant differences in the overall mean levels of performance found for "constant" member firms and for "shifting" member firms. Further, we test for significant differences in the variances in performance levels (performance homogeneity) found within both categories of strategic group member firms. In addition, we conduct the statistical tests of our hypotheses during a period of industry stability and a period of industry instability to investigate whether or not environmental stability or instability have any systematic impact on the relationship between strategic persistence and change to performance.

Hypothesis 1: During conditions of industry stability, the constant firm sets and the shifting firm sets will not exhibit different levels of performance.

Hypothesis 2: During conditions of industry instability, the constant firm sets and the shifting firm sets will not exhibit different levels of performance. 
Hypothesis 3: During conditions of industry stability, the constant firm sets and the shifting firm sets will not exhibit different levels of performance homogeneity.

Hypothesis 4: During conditions of industry instability, the constant firm sets and the shifting firm sets will not exhibit different levels of performance homogeneity.

\section{Methods}

\section{Industry Sample}

Two prior studies specifically considered the issue of strategic groups in the banking industry. Amel and Rhoades (1987) investigated whether or not strategic groups could be found in the banking industry, based on a selection of banking industry-specific variables. Reger (1988) investigated whether or not managers in the banking industry cognitively identified strategic groups and their firm members. Results from these studies suggested that strategic groups do exist in the banking industry, and that the concept of strategic groups is cognitively meaningful to practitioners. Further, the banking industry lends itself well to the issues being considered in this study as this industry has gone through significant periods of stability and instability over the past 25 years. The banking industry files contained on COMPUSTAT provided the sample population for this study. The COMPUSTAT banking file contains banks of all sizes, as well as from all regions throughout the United States. This file provided a sample of 62 banks for the stable time period of study and 109 banks for the unstable time period.

\section{Time Period Selection}

The research issues of this paper were investigated within the contexts of a period of stability and a period of instability for the banking industry as a whole. Dess and Beard (1984) define industry environmental stability as a condition where there are only small amounts of change in the key strategic dimensions or conditions facing a particular industry. Thus, industry stability should lead to a condition of industry understanding and predictability.

Three dimensions have become standard in the typing of the environment: munificence, dynamism or instability, and complexity (Dess and Beard, 1984). Keats and Hitt (1988), in their study of the impact of the environmental dimensions of munificence, instability, and complexity on organizations, found that the dimension of instability had a greater impact on the behavior and subsequent performance of an organization than did either of the other two dimensions. Therefore, the dimension of instability was chosen as the most appropriate to the focus of this study.

This study established time periods of relative environmental instability and stability in a manner consistent with the approach utilized by Tosi, 
Aldaq, and Storey (1973), Snyder and Glueck (1982), and Keats and Hitt (1988). Due to the major role of interest rates in both the revenues and expenses of banks in general the measure of instability was a coefficient of variation, calculated on the prime rate as reported by the Federal Reserve Board, since interest rate changes have been noted as a major source of environmental instability in the banking industry. This study considered the entire period of 1968-1987, the time period on the 20 year banking data file available from COMPUSTAT. From the analysis of this data file two distinct time periods were found, one which best reflected a period of industry stability - 1968-1972, and one which best reflected a period of industry instability - 1978-1982.

By way of comparison, Snyder and Glueck (1982) reported coefficients of variation for industries ranging from .24 in the electronics industry (the most unstable) to .10 in the confectionery products industry (the most stable). In our study, the coefficients of variation for the two time periods selected for the study were .06 for the time period of 1968-1972, and .24 for the time period of 1978-1982, providing, therefore, measures for instability and stability in the banking industry that equalled or exceeded those of the Snyder and Glueck study. Furthermore, the choice of these two time periods were externally validated by the opinion of industry specialists (Compton, 1987; Haraf and Kushmeider, 1987), and by the charting of bank failure rates and changes in the prime rate over time. For example, bank failure rates more than doubled during the unstable period of time, relative to that of the stable period of time; and prime rates, which remained basically stable during 1968-1972, fluctuating less than 3 percentage points, ranged over 12 percentage points during the 1978-1982 time period.

\section{Variable Selection}

This study used a list of scope and resource deployment variables selected by academics and practitioners for their ability to reflect the unique strategic decision alternatives available to managers in the banking industry. The sources for this variable list include Amel and Rhoades (1987), Pohlman (1985), Reger (1988), Rosenblum and Pavel (1985), Sinkey (1989) and professors Scott MacDonald and Steven Sears of the Institute for Banking and Finance Studies at Texas Tech University.

The following variables, used in the present study, reflect the strategic scope and resource deployment choices generally available to banks. These variables were derived from the COMPUSTAT annual bank file for the time periods of 1968-1972 and 1978-1982.

Scope variables:

(1) Loans/total assets

(2) Treasury securities/total assets

(3) State and local government securities/total assets

(4) Federal funds/total assets 
(5) Trust revenue/total assets

(6) Time deposits/total assets

(7) Demand deposits/total assets

(8) Foreign deposits/total assets

Resource deployment variables:

(9) Premises, furniture, and equipment/total assets

(10) Officer and employee salaries and wages/total assets

\section{Performance Variable Selection}

Pohlman (1985) identified the following measures of performance that are of specific value to the banking industry and which are used in this study:

(1) Return on equity

(2) Return on assets

(3) Profit margin

While the limitations of accounting data have been noted by Barney and Hoskisson (1990), the variables selected for this study reflect standard practice in strategic group studies, as a review of the 52 strategic group studies since 1972 indicates that over forty of the studies utilized accounting data as the basis for cluster analysis (Dixon, 1994). Further, in an effort to minimize error, all clustering variables and the resulting groups were subjected to validation by industry expert opinion.

\section{Cluster Analysis Procedure}

For this study, firms within the banking services industry were clustered into strategic groups for each year of the two five-year periods via a non-hierarchical and disjointed clustering technique. A question relative to the choice of a cluster analysis procedure is whether one wishes to obtain disjointed clusters where each firm is found within one and only one cluster.

As the major focus of this study was to investigate the influence of a firm's constant, versus shifting, membership in a strategic group on performance, a cluster analysis technique was needed that forces closed strategic group boundaries, thereby allowing firms to belong to only one strategic group at any point in time. The SAS Institute, Inc. procedure of PROC FASTCLUS provides the non-hierarchical and disjointed cluster analysis best suited for the issue of the present study and was for the above-stated reasons deemed the most appropriate clustering technique to use in this study. The determination of the appropriate number of strategic groups for each year of the study was based on a review of the $\mathrm{R}^{2}$, the Cubic Clustering Criterion value, and the Psuedo- $F$ value generated for each iteration of the clustering technique. A ruleof-thumb identified by Fiegenbaum (1987) for the $R^{2}$ values as a cut-off point in cluster analysis is that one should not increase the number of clusters past the point where the $\mathrm{R}^{2}$ values are increasing at a rate of less than $5 \%$. The PROC FASTCLUS procedure generates for each number of strategic groups a Cubic Clustering Criterion and a Psuedo-F statistic. These two statistics indi- 
cate the appropriate number of strategic groups as being that point at which these two statistical measures peak.

\section{Strategic Group Membership Status}

Sixty-two banks during the stable time period of 1968-1972, and 109 banks during the unstable time period of 1978-1982, were clustered by their strategic profile, as indicated by the cluster analysis loadings on each of the strategic variables, into five strategic groups (consisting of $4,7,8,21$, and 22 banks each) during the stable time period and into three strategic groups (consisting of 12,38 , and 59 banks each) during the unstable time period. Following the establishment of the appropriate number of strategic groups, as determined by the procedure discussed in the section above, these resulting groups were then further validated by industry expert opinion. Then for the two time periods of study, sub-group categories of constant strategic group firm members and shifting strategic group firm members were established for each of the years 1968-1972 and 1978-1982. This was accomplished by a MOBIUS procedure which compares the location of all firms included in strategic group 1 in year $\mathrm{N}$ to their strategic group location in year $\mathrm{N}+1$ (Sudharshan, Fiegenbaum, and Thomas, 1991). The firms located on the diagonal for the entire five years of each period (stable and unstable) are the constant member firms; all others are categorized as shifting member firms. This procedure was done for all strategic groups for each of the five years of the stable period of 1968-1972 and each of the five years of the unstable period of 1978-1982.

\section{Hypotheses Testing Procedures}

Performance means differences, as indicated in hypotheses 1 and 2, are analyzed by an ANOVA test available in PROC GLM of SAS. Performance variances, as indicated in hypotheses 3 and 4 , are analyzed by an $F$ test available in PROC TTEST of SAS.

\section{Results}

\section{Identification of Strategic Groups}

The determination of the appropriate number of strategic groups for each year of the study was based on a review of the $\mathrm{R}^{2}$, the Cubic Clustering Criterion value, and the Psuedo- $F$ value generated by the cluster analysis procedure. For the stable period of 1968-1972 five major strategic groups were consistently found. The groups as established by the clustering technique were verified by a recognized banking industry expert. A review of the strategic profiles established by the relative weight given each of the strategic variables in the clustering technique utilized in this study resulted in the following groups being identified. They were: (1) commercial banks seeking core deposits, such as certificates of deposits, (2) smaller local banks acting as good corporate citizens by investing heavily in local securities offerings, (3) traditional 
banks following a match-funding strategy with loans equaling deposits, (4) investment banks, and (5) money center banks seeking foreign deposits. Using the identical procedure as above described for the unstable period of 19781982 , three major strategic groups were consistently found to be operating within the banking industry. They were identified as: (1) banks which followed the conservative policy of loaning their excess liquidity to other banks, (2) aggressive commercial banks offering short term loans in an effort to maximize gains from rapidly changing interest rate changes,and (3) money center banks seeking foreign deposits.

\section{Differences in Performance Means}

To test for differences in performance means between constant and shifting strategic group firm members, a two-factor model was used. Factor 1 indicated a firm's status as either a constant or a shifting strategic group firm member. Factor 2 indicated the specific strategic group of which each firm was a member. The analysis was done as detailed for each of the 10 years of the study on three performance variables: return on equity, return on assets and before-tax profit margin. Seeking to further our understanding of whether there are performance consequences of strategic group membership, this procedure allowed an investigation into the statistical impact of a variety of performance measures. For the stable time period of 1968-1972, hypothesis 1 was rejected one out of five years for the return-on-equity measure, four out of five years for the return-on-assets measure, and three out of five years for the before-tax profit measure (Table 1). During this period of industry stability, statistically significant differences between mean performance levels for the sub-groups of constant member firms and shifting member firms occurred a little over 50\% of the time, depending upon the measure of performance chosen.

Table 1

Performance Mean Differences Between Constant and Shifting Strategic Group Firm Members: Stable Period

\begin{tabular}{lllccc}
$\begin{array}{l}\text { Performance } \\
\text { Variables }\end{array}$ & 1968 & 1969 & 1970 & 1971 & 1972 \\
\hline ROE & $1.99^{*}$ & $2.60^{* *}$ & $1.84^{*}$ & .52 & 1.43 \\
ROA & $9.18^{* *}$ & $7.54^{* * *}$ & $6.91^{* * *}$ & $1.76^{*}$ & $3.11^{* * *}$ \\
Profit & $6.62^{* * *}$ & $3.86^{* * *}$ & $2.13^{* *}$ & .52 & 1.13 \\
& & & & & \\
$*$ P-value $<.10$ & & & & & \\
$* *$ P-value $<.05$ & & & & & \\
$* * *$ P-value $<.01$ & & & & &
\end{tabular}

The results for the unstable time period of 1978-1982, however, do not indicate a general rejection of hypothesis 2 (Table 2). For each of the three 
performance variables, the null hypothesis was rejected only four times out of the fifteen cases available. This would indicate that performance differences between constant and shifting strategic group firm members essentially disappear during times of industry environmental instability.

Table 2

Performance Mean Differences Between Constant and Shifting Strategic Group Firm Members: Unstable Period

\begin{tabular}{llllll}
$\begin{array}{l}\text { Performance } \\
\text { Variables }\end{array}$ & 1978 & 1979 & 1980 & 1981 & 1982 \\
\hline ROE & 1.01 & 1.19 & 1.37 & $3.44^{* * *}$ & 1.06 \\
ROA & 1.55 & 1.26 & $1.67^{*}$ & 1.12 & 1.47 \\
Profit & $1.95^{*}$ & 1.41 & $1.70^{*}$ & 1.04 & $1.66^{*}$ \\
& & & & & \\
* P-value $<.10$ & & & & \\
** P-value $<.05$ & & & &
\end{tabular}

\section{Equality of Performance Variance}

For each of the five years of the stable time period (1968-1972) and the unstable time period of the study (1978-1982), an "F" statistic was computed, testing the null hypothesis of equality of variance for the three performance measure means between the sub-group of constant member firms and the subgroup of the shifting member firms. Table 3 provides the results of this test for the stable period of 1968-1972. For the performance measure of returnon-equity, hypothesis 3 was not rejected in any year investigated, indicating no statistically significant differences in the variance for this measure between the constant and shifting firm sets. The performance measure of return-on-assets rejected the hypothesis in three out of the five years of the stable period. Therefore, for the stable time period of 1968-1972, there is little statistical evidence supporting unequal performance variances between the constant member firm sub-groups and the shifting member firm sub-groups.

Table 3

Constant versus Shifting Strategic Group Firm Sets Test of Equality of Variance: Stable Period

\begin{tabular}{llllll}
$\begin{array}{l}\text { Performance } \\
\text { Variables }\end{array}$ & 1968 & 1969 & 1970 & 1971 & 1972 \\
\hline ROE & 1.13 & 1.63 & 1.08 & 1.14 & 1.04 \\
ROA & $4.07^{* * *}$ & $3.63^{* * *}$ & $2.90^{* * *}$ & 1.06 & 1.54 \\
Profit & 1.78 & 1.38 & 1.44 & 1.09 & 1.17 \\
& & & & & \\
* P-value $<.10$ & & & & \\
** P-value $<.05$ & & & & \\
*** P-value $<.01$ & & & &
\end{tabular}


Table 4 provides the results for the testing of equality of variance for the three performance measures between the constant and shifting member firm sets for the unstable industry time period of 1978-1982. For the performance measure of return-on-equity hypothesis 4 failed to be rejected four out of the five years of this period. For the return-on-assets measure hypothesis 4 again failed to be rejected four out of five years. The hypothesis failed to be rejected for the before-tax profit margin measure two out of five years. Again, the statistical results generally failed to support unequal performance variances between the sub-groups of constant and shifting member firm sets.

Table 4

Constant versus Shifting Strategic Group Firm Sets Test of Equality of Variance: Unstable Period

\begin{tabular}{llllll}
$\begin{array}{l}\text { Performance } \\
\text { Variables }\end{array}$ & 1978 & 1979 & 1980 & 1981 & 1982 \\
\hline ROE & 1.01 & 1.19 & 1.37 & $3.44^{* * *}$ & 1.06 \\
ROA & 1.55 & 1.26 & $1.67^{*}$ & 1.12 & 1.47 \\
Profit & $1.95^{*}$ & 1.41 & $1.70^{*}$ & 1.04 & $1.66^{*}$ \\
& & & & & \\
* P-value $<.10$ & & & & & \\
** P-value $<.05$ & & & & & \\
*** P-value $<.01$ & & & &
\end{tabular}

\section{Discussion}

This study suggests that, within strategic groups, firms that have remained constant members will have different performance characteristics than will be found for those firms that have not been constant members of a particular strategic group over a given period of time. For the stable time period of 19681972, constant member firms exhibited higher performance levels than did shifting member firms in $73.3 \%$ of the cases. Further, during the unstable period of time, constant member firms exhibited higher performance levels than did shifting firms in $72.5 \%$ of the cases.

The empirical results of this study suggest, therefore, that the inconsistent findings in previous studies between strategic group membership and performance could be partly due to researchers not controlling for the confounding influences of strategic group composition. Our results suggest that, within each strategic group, firms that have remained members over time will have higher levels of performance than will firms that are newer to the strategic group, and especially so during times of industry environmental stability. Therefore, strategic groups with a high ratio of constant to shifting member firms can be expected to have different performance characteristics than would strategic groups with a low ratio of constant to shifting member firms. This finding is consistent with the general idea of strategic persistence, or "practice makes 
perfect." It is reasonable to expect that firms will do that better which they have experience doing.

Further, sub-groups of constant member firms were expected to exhibit significantly less variance in their performance measures than found for the sub-groups of shifting member firms. However, little statistical support was found for this proposition for either the stable time period of 1968-1972 or the unstable time period of 1978-1982.

\section{Conclusion}

By tracking the strategic group membership of firms over two five-year time periods, this study supported the proposition that strategic groups do appear to exist in terms of collections of firms that exhibit, over significant periods of time, a tendency to make similar strategic decisions. This would suggest that, within an industry, strategic groups do have an impact on the strategic choices and decisions made by the firms that comprise that industry.

While firms can change their strategic group membership, and by definition their strategies, this study found that the highest performers were those that stayed the course, i.e., firms that pursued over a longer period of time a single strategy outperformed those firms that switched strategies over the time periods of the study.

Further, this research raises issues with one of the fundamental tenets of strategy, that a firm attempt to co-align itself with its environment. Prior research suggests that firms can exercise strategic choice in choosing their strategic orientation and that they can change their strategies as they attempt to achieve this environmental alignment. However, research also suggests that strategic change to achieve such an alignment will not necessarily result in superior performance, relative to those that do not change. This is consistent with other work on generic strategies that suggests firms without a coherent strategy will have lower levels of performance than will firms which follow a consistent strategy. Based on the results of this study, we would suggest that strategic persistence appears to be a more viable approach to achieving superior financial performance than is strategic change.

We do not suggest that strategic change in an effort to enhance environmental co-alignment, or fit, is not a useful concept. Rather, that strategic change, due either to a lack of necessary organizational capabilities and/or the misreading of the environment, is as likely to cause a misfit as it is to create a fit.

\section{References}

Amel, D. and S. Rhoades. Strategic Groups in Banking. Working paper no. 87-1. Financial Structure Section, Division of Research and Statistics. Board of Governors of the Federal Reserve System, 1987. 
Barney, J. and R. E. Hoskisson. "Strategic Groups: Untested Assertions and Proposals." Managerial and Decision Economics 11 (1990): 187-198.

Compton, E. The New World of Commercial Banking. Lexington, MA: Lexington Books, 1987.

Cool, K. and D. Schendel. "Strategic Group Formation and Performance: U.S. Pharmaceutical Industry, 1963-1982." Management Science 33 (1987): 1102-1124.

Dess, G. and W. D. Beard. "Dimensions of Organizational Task Environments." Administrative Sciences Quarterly 29 (1984): 52-73.

Dixon, R. "Performance Homogeneity among Strategic Groups Constant Member Firm Sets and Shifting Member Firm Sets in the Banking Industry." Ph.D Dissertation, Texas Tech University, 1994.

Fiegenbaum, A. "Dynamic Aspects of Strategic Groups and Competitive Strategy: Concepts and Empirical Examination in the Insurance Industry." Ph.D. Dissertation, University of Illinois at Urbana-Champaign, 1987.

Fiegenbaum, A. and H. Thomas. "Strategic Groups as Reference Groups: Theory, Modeling, and Empirical Examination of Industry and Competitive Strategy." Strategic Management Journal 16(6), (1995): 461-476.

Galbraith, J. "Strategy and Organizational Planning." Human Resource Planning, (1983): 63-77.

Haraf, W. and R. Kushmeider. Restructuring Banking and Financial Services in America. Washington, DC: American Enterprise Institute for Public Policy Research, 1987.

Hunt, M. "Competition in the Major Home Appliance Industry 1960-1970." Ph.D. Dissertation, Harvard University, 1972.

Keats, B. and M. Hitt. "A Causal Model of Linkages among Environmental Dimensions, Macro Organizational Characteristics, and Performance." Academy of Management Journal 31(3), (1988): 570-598.

McGee, J. and H. Thomas. "Strategic Groups: A Useful Linkage between Industry Structure and Strategic Management." Strategic Management Journal 6 (1986): 141160.

Miles, R.E. and C.C. Snow Organization Strategy, Structure, and Processes. New York: McGraw-Hill, 1978.

Mintzberg, H. and J. Quinn. The Strategy Process. New Jersey: Prentice Hall, 1991. 
Parnell, J. "Strategic Consistency versus Flexibility: Does Strategic Change Really Enhance Performance?" American Business Review 12(2), (1994): 22-29.

Peters, T. "Strategy Follows Structure: Developing Distinctive Skills." California Management Review (Spring, 1984): 111-125.

Pohlman, J. "A Framework for Strategic Planning." In Handbook for Banking Strategy, eds. R. Aspinwall and R. Eisenbeis. New York: John Wiley \& Sons, 1985.

Porter, M. Competitive Strategy. New York: The Free Press, 1980.

Reger, R. "Competitive Positioning in the Chicago Banking Market: Mapping the Mind of the Strategist." Ph.D. Dissertation, University of Illinois at Urbana-Champaign, 1988.

Rosenblum, H. and C. Pavel. "Banking Services in Transition: The Effects of Nonbank Competitors." In Handbook for Banking Strategy, eds. R. Aspinall and R. Eisenbleis. New York: John Wiley \& Sons, 1985.

Sinkey, J. Commercial Bank Financial Management in the Financial Services Industry. New York: MacMillan, 1989.

Snyder, N. and W. Glueck. "Can Environmental Volatility be Objectively Measured?" Academy of Management Journal 25 (1982): 185-192.

Thomas, H. and N. Venkatraman. "Research on Strategic Groups: Progress and Prognosis." Journal of Management Studies 26(6), (1988): 537-556.

Tosi, H., R. Aldaq, and R. Storey. "On the Measurement of the Environment: An Assessment of the Lawrence and Lorsch Environmental Uncertainty Questionnaire." Administrative Sciences Quarterly 18 (1973): 27-36.

Rolf D. Dixon, (Ph.D., Texas Tech University), is an Assistant Professor of Management at West Texas A\&M University where he is teaching Strategic Management and Contemporary Management Problems. Research areas of interest includes strategic groups as predictors of organizational behavior and performance and management issues in a cross-national environment. Prior research has appeared in such journals as Health Care Strategic Management Journal and the Journal of Transnational Management Development.

Kimberly B. Boal, (Ph.D., University of Wisconsin), is an Associate Professor of Management at Texas Tech University. Currently he is visiting at the Pennsylvania State University where he is teaching Organizational Theory and researching problems associated with integrating merged companies. Prior research has appeared in such journals as Strategic Management Joumal, Academy of Management Joumal, Joumal of Management, Organizational Behavior and Human Performance, and Leadership Quarterly, as well as several scholarly book chapters. 